\title{
Randomness in the RAWP formula: the reliability of mortality data in the allocation of National Health Service revenue
}

\author{
S. R. PALMER AND P. A. WEST \\ From the Department of Community Medicine, St. Thomas's Hospital Medical School \\ P. DODD \\ From the South-east Thames Regional Health Authority
}

\begin{abstract}
A corner-stone of the recommendations by the Resource Allocation Working Party (RAWP) ${ }^{1}$ for the allocation of the non-psychiatric service budget was the introduction of standardised mortality ratios (SMRs) as proxy measures of regional variations in morbidity. The appropriateness of this measure has been heavily criticised but it remains in the present allocation method. However, the introduction of seemingly objective measures such as SMRs may give a misleading impression of accuracy. Fluctuations in death rates unrelated to the general force of mortality or to factors relevant to health services require that each SMR should be considered as a sample taken from a range of possible SMRs which are distributed about the true value.
\end{abstract}

The problem of the reliability of SMRs is accentuated by the use of SMRs disaggregated by condition groups corresponding to the chapter divisions of the International Classification of Diseases (ICD) and this is one of the chief difficulties in implementing the RAWP recommendations at subregional level. The working party acknowledged this problem in its report but claimed ( $p$ 40) that 'condition-specific SMRs can be used at area and district level with some loss of reliability due to small numbers involved. Sensitivity tests indicate, however, that the results will still be closer in most cases to the notionally 'correct' result than would be the case if another measure such as overall SMRs were applied'. The sensitivity tests referred to have not been published but several health authorities have carried out their own statistical analyses.

Such a lack of quantitative support is not confined to RAWP. There is an obvious deficiency of data in many criticisms of it. On the question of the reliability of SMRs calculated on small populations, Geary ${ }^{2}$ and Ferrer $e t a l^{3}$ do support their views with statistical analyses, but these are used to establish the possibility that problems exist rather than to provide estimates of the scale of the problems.
In this paper we provide an empirical basis for assessing the importance of the statistical significance of SMRs in resource allocation decisions. The method used centres on the calculation of the variance of SMRs and the implications of excluding statistically insignificant deviations of SMRs from the average of 100. To place the discussion in its $\omega$ appropriate policy context we present first a briep review of current national and regional allocatio of policy.

ALLOCATION POLICY AND SMRS Regional target shares of the non-psychiatri inpatient budget are calculated by the Department 0 Health and Social Security from (a) region populations (b) estimates of national expenditure pẹP $\overrightarrow{0}$ caput by age and sex in each group of conditions $\infty$ comprising the ICD chapter divisions and (c) regional SMRs for each $I C D$ condition group. Of the 16 relevant non-psychiatric $I C D$ chapters (1-4 and 6-17), two are isolated for modification because the small number of deaths occurring would make the SMR 'unlikely to give a good guide to morbidity' (RAWP report ${ }^{1} \mathrm{p} 21$ ). These are chapter 12 (diseases of the skin), where all SMRs are set at 100, and chapter 11 (diseases related to pregnancy and childbirth), where standardised fertility ratios are used as a more appropriate indicator of regional variations in required provision. Thus at national level the existence of problems relating to small numbers of deaths is acknowledged.

RAWP envisaged that the method of calculating regional revenue targets would also be used by regions to calculate district targets. To a large extent this has occurred in practice, but with some noteworthy exceptions. Resource allocation working parties set up by individual regions have expressed varying degrees of concern about the inclusion of a mortality measure for morbidity adjustment, and this is reflected in their allocation proposals. One region 
has decided to exclude SMRs altogether from the calculation of district budget allocations, on the grounds that their use is inappropriate. Another region has compromised between conflicting views on the use of SMRs by giving its districts $50 \%$ of the allocation calculated with SMRs included and 50\% without them (one dissenting member of the regional party submitted a minority report favouring the full use of SMRs). All the remaining regions on which we have information have used SMRs in their calculations, though in varying forms. Broadly, they may be divided into two groups: those using SMRs for each separate chapter of the ICD classification (as used nationally by the DHSS, with the exception of skin diseases and pregnancy) and those using a single all-condition SMR.

Decisions on the degree of disaggregation of the SMR can influence revenue allocations to districts because the comparatively small numbers of deaths at district level make some SMRs for individual causes highly sensitive to random influences. All regions are aware of this and have endeavoured to use as many years of data as possible, usually based on post-reorganisation averages. However, as we show elsewhere in this paper, even three-year-based SMRs for several chapters of the $I C D$ are statistically unreliable because of the potentially large influence that might be exerted at district level by random changes in the numbers of deaths.

A sophisticated compromise has been implemented by two regions. Only statistically significant SMRs for $I C D$ chapters at district level are used individually; the remaining chapters are aggregated into a single SMR.

Finally, while the national RAWP allocations are developed from average hospital utilisation rates for diseases in each $I C D$ chapter and regional SMRs, several regions have developed allocations based on specialties and specialty utilisation rates. This enables utilisation rates to be linked to the revised specialty cost-per-case estimates provided recently by the DHSS for the regional and subregional adjustments for cross-boundary flows. The difficulty with a specialty-based calculation of district allocations is that no specialty-specific SMRs can be calculated because of the heterogeneity of cases in the two largest specialties, general medicine and general surgery. Therefore, aggregated SMRs are used, even though for some conditions the ICD chapter-specific SMR would be statistically reliable.

To summarise, of the 11 regions on which we have sufficiently detailed information, seven are applying the RAWP approach to their subregional allocations using ICD chapter-specific SMRs. Of these, two make explicit adjustments for the statistical insignificance of some $I C D$ chapter-specific SMRs at district level. Of the remaining four regions, one has used SMRs but has not weighted them fully, two have fully applied all-condition SMRs for districts or areas to utilisation-adjusted populations, and one has rejected their use altogether.

\section{Method}

The standardised mortality ratio (SMR) is defined as $\frac{\text { Observed deaths (in study population) }}{\text { Expected deaths (if the age-specific }}=\frac{\mathrm{O}}{\mathrm{E}}$ mortality experience of the standard population were applied)

and is usually expressed as a percentage.

Many authors have followed the example of Armitage $e^{4}$ in assuming that the observed deaths in each population subgroup are observations from a Poisson distribution. This suggests the following approximation to the variance:

$$
\operatorname{Var}\left(S_{M R}\right)=O_{i} / E_{i}^{2}
$$

Hence, assuming the relevant distributions, SMR will be significantly different from 100 if

$$
|(\mathrm{SMR})-100|>1.96\left(0_{\mathrm{i}} / \mathrm{E}_{\mathrm{i}}^{2}\right)
$$

A more sophisticated method for calculating the variance of a mortality index, proposed by Chiang, ${ }^{5}$ was found to give almost identical estimates of variance and so in the subsequent analysis the simpler method of calculation is used.

The 1974-6 condition-specific SMRs were calculated using the following data.

(1) 1974,1975 , and 1976 mortality by age group and ICD 8th revision chapters for England and regional health authorities. ${ }^{678}$ We have omitted chapters 5,11 , and 12 in common with RAWP.

(2) 1975 mid-year estimates of population for England and the 14 regional health authorities.

SMRs and their variances were also calculated for the districts of one region. The districts are tabulated in a random order and are not identified to preserve confidentiality.

Given that many SMRs currently being used for revenue allocation fail our test of significance, and that their exclusion from the RAWP calculations would produce changes in the final distribution of resources, especially at subregional level, what can be done to minimise this effect of statistical non-significance? The remedy suggested by RAWP was to aggregate a number of years' data when calculating the value of the SMR. It was suggested that eventually a maximum of 10 years' mortality data at district level should be used in the calculation of subregional targets.

The maximum amount of data which has been used nationally in the production of target allocations covers three years; mostly the years 1975-1977. No 
data from before 1974 can be used because of the changes in health authority boundaries which took place during that year.

As a crude approximation, the variance of an SMR is inversely proportional to the numbers of years of data used. The reduction in the standard deviation which would follow if 10 years' data were used instead of three years' data is therefore only very slightly better than the improvement brought about by using three years' data instead of one year's. To investigate this point further, we have estimated the number of years' data required to produce significant SMRs (at the 5\% level) for a model region, area, and district. These estimates were constructed on the basis of the following assumptions:

(1) The total populations of the region, area, and district are 3500000,700000 , and 200000 respectively.

(2) The age structure of each of these populations is the same as the national age structure.

It follows directly that the expected number of deaths in one year in each of the three groups is equal to the national number of deaths multiplied by the ratio of total populations. If we further assume that the number of observed deaths is the same each year, we can calculate the number of years' data which would be required for a given SMR to be significant at a given level. This technique was used in compiling Tables 4 and 5 .

\section{Results}

Table 1a shows the number of regions which have statistically significant condition-specific SMRs $(P<0 \cdot 05)$. All 14 regions have significant SMRs for cardiovascular deaths. The range of variation of SMRs is relatively small (Table $1 b$ ) but so also is the range of variation of the standard deviation. By contrast, the range of variation of SMRs for deaths due to musculoskeletal disorders is greater, but because the standard deviations of the SMRs are also greater only two regional SMRs reach statistical significance.

More than half the sex- and condition-specific SMRs calculated for the region using three years' data are not significantly different from 100 at the $5 \%$ level. If these SMRs differ from 100 only by chance, what may be the likely distorting effects on the target allocations? To illustrate the possible effect, we calculated regional revenue target allocations for non-psychiatric inpatients (NPIP) using the 1978-9 utilisation weights, 1975 populations, and 1974-76 SMRs (a) using all SMRs and (b) using SMRs significant at the $5 \%$ level only. All changes reported here refer to the NPIP target. This comprises 55\% of total revenue, so changes in terms of the total regional targets are roughly half the size reported.
Table 1(a) Regional condition-specific SMRs 1974-76: number of regions with significant $(P<0.05)$ SMRs

\begin{tabular}{lcc}
\hline Condition group & Male & Female \\
\hline Infective & 8 & 11 \\
Neoplasms & 11 & 10 \\
Endocrine & 4 & 8 \\
Haemopoitetic & 4 & 10 \\
Nervous system & 5 & 6 \\
Circulatory & 14 & 14 \\
Respiratory & 11 & 11 \\
Digestive & 8 & 8 \\
Urogenital & 7 & 7 \\
Childbirth & - & 14 \\
Musculoskeletal & 2 & 2 \\
Congenital & 1 & 0 \\
Perinatal & 8 & 8 \\
Symptoms and ill-defined & 10 & 9 \\
lnjuries and accidents & 9 & 10
\end{tabular}

Table 1(b) Regional condition-specific SMRs 1974-76: extent of inter-regional variation

\begin{tabular}{|c|c|c|}
\hline Condition group & Range of SMRs & $\begin{array}{l}\text { Range of standard } \\
\text { deviation of SMRs }\end{array}$ \\
\hline Infective & $61 \cdot 9-119 \cdot 6$ & $4 \cdot 5-7 \cdot 1$ \\
\hline Neoplasms & $89 \cdot 5-115 \cdot 0$ & $0 \cdot 7-1 \cdot 1$ \\
\hline Endocrine & $82 \cdot 9-112 \cdot 4$ & $3 \cdot 8-5 \cdot 8$ \\
\hline Haemopoietic & $78 \cdot 1-124 \cdot 3$ & $7 \cdot 1-12 \cdot 2$ \\
\hline Nervous system & $87 \cdot 0-118 \cdot 8$ & $3 \cdot 4-5 \cdot 0$ \\
\hline Circulatory & $86 \cdot 1-116 \cdot 0$ & $0.8-0.5$ \\
\hline Respiratory & $77 \cdot 2-121 \cdot 9$ & $0.9-1.4$ \\
\hline Digestive & $86 \cdot 5-116 \cdot 7$ & $2 \cdot 2-3 \cdot 5$ \\
\hline Urogenital & $88 \cdot 1-112 \cdot 8$ & $2 \cdot 9-4 \cdot 5$ \\
\hline Musculoskeletal & $84 \cdot 4-134 \cdot 1$ & $7 \cdot 3-12 \cdot 5$ \\
\hline Congenital & $89 \cdot 1-109 \cdot 3$ & $4.0-6.7$ \\
\hline Perinatal & $75 \cdot 9-115 \cdot 4$ & $3 \cdot 8-5 \cdot 4$ \\
\hline Symptoms and ill-defined & $70 \cdot 5-129 \cdot 3$ & $5.0-9.7$ \\
\hline Injuries and accidents & $89 \cdot 5-113 \cdot 1$ & $1 \cdot 7-2 \cdot 7$ \\
\hline
\end{tabular}

The change in a region's NPIP revenue target when $\overrightarrow{\vec{\varphi}}$ non-significant SMRs are omitted is expressed as a percentage of the revenue it would have received using all SMRs (Table 2). The changes in allocation targets are in the range $+1 \cdot 1 \%$ to $-0 \cdot 8 \%$. For 11 of the 14 regions the changes are in the opposite

Table 2 Change in regional shares of non-psychiatric inpatient revenue budget when non-significant SMRs are omitted from national calculation

\begin{tabular}{lccc}
\hline & $\begin{array}{l}\text { Target \% of } \\
\text { budget with } \\
\text { all SMRs } \\
\text { used }\end{array}$ & $\begin{array}{l}\text { Target \% of } \\
\text { budget with } \\
\text { significant SMRs } \\
\text { used }\end{array}$ & $\begin{array}{l}\text { \% change in } \\
\text { regional targets }\end{array}$ \\
Regions & 7.06 & 7.01 & -0.7 \\
\hline Northern & 7.78 & 7.76 & -0.3 \\
Yorkshire & 9.53 & 9.52 & -0.1 \\
Trent & 3.81 & 3.83 & +0.5 \\
East Anglia & 6.96 & 7.04 & +1.1 \\
North-west Thames & 8.18 & 8.14 & -0.5 \\
North-east Thames & 7.92 & 7.97 & +0.6 \\
South-east Thames & 6.16 & 6.14 & -0.3 \\
South-west Thames & 5.44 & 5.47 & +0.6 \\
Wessex & 4.10 & 4.14 & +1.0 \\
Oxford & 6.96 & 6.99 & +0.4 \\
South-western & 10.73 & 10.69 & -0.4 \\
West Midlands & 5.56 & 5.56 & - \\
Mersey & 9.82 & 9.74 & -0.8 \\
North-western & & & \\
\hline
\end{tabular}


direction to the original effect of introducing SMRs into the formula. At district level the effect of omitting non-significant SMRs will be greater due to the larger sampling errors of the SMRs. We have examined this effect in one region, working on the assumption that the supraregional RAWP methodology is to be used to calculate district targets. Table 3 shows that the percentage change in a district's NPIP revenue target is in the range $+3 \cdot 8 \%$ to $-4 \cdot 5 \%$. Only two district allocation targets change by less than $1 \%$.

Table 3 Change in non-psychiatric inpatient revenue target allocations to districts when non-significant SMRs are omitted

\begin{tabular}{|c|c|c|c|}
\hline District & $\begin{array}{l}\text { District target } \\
\text { \% of budget } \\
\text { with all SMRs used }\end{array}$ & $\begin{array}{l}\text { District target } \% \text { of } \\
\text { budget with } \\
\text { significant } \\
\text { SMRs used }\end{array}$ & $\begin{array}{l}\text { \% change in share } \\
\text { of regional } \\
\text { revenue }\end{array}$ \\
\hline 1 & 9.65 & 9.78 & $+1 \cdot 3$ \\
\hline 2 & 6.41 & 6.53 & +1.9 \\
\hline 3 & $4 \cdot 57$ & 4.69 & +2.6 \\
\hline 4 & $7 \cdot 18$ & 6.99 & -2.6 \\
\hline 5 & 8.47 & 8.39 & -0.9 \\
\hline 6 & 5.91 & 5.65 & $-4 \cdot 4$ \\
\hline 7 & $4 \cdot 73$ & 4.67 & $-1 \cdot 3$ \\
\hline 8 & $7 \cdot 52$ & 7.68 & $+2 \cdot 1$ \\
\hline 9 & $5 \cdot 26$ & $5 \cdot 46$ & +3.8 \\
\hline 10 & $5 \cdot 10$ & $5 \cdot 21$ & $+2 \cdot 2$ \\
\hline 11 & $5 \cdot 55$ & $5 \cdot 53$ & -0.4 \\
\hline 12 & $7 \cdot 13$ & $7 \cdot 32$ & +2.7 \\
\hline 13 & $5 \cdot 52$ & $5 \cdot 33$ & -3.4 \\
\hline 14 & $7 \cdot 16$ & 6.84 & $-4 \cdot 5$ \\
\hline 15 & 4.03 & $4 \cdot 17$ & $+3 \cdot 5$ \\
\hline 16 & $5 \cdot 79$ & $5 \cdot 73$ & $-1 \cdot 0$ \\
\hline
\end{tabular}

A health authority's SMRs may not reach conventional levels of statistical significance when calculated from the few years' data available since 1974, yet those SMRs may be reflecting real mortality differences. If the concept of statistical significance is to be applied to RAWP then it is of interest to know how many years' data would be needed to ensure statistical significance for SMRs of given values.

To tackle this problem in a convenient form, we have considered three hypothetical populations of approximately region, area, and district size. For each $I C D$ group and for given SMR values, we have calculated the number of years' data needed for these SMR values to attain statistical significance (Table 4). At regional level, using three years' data, all condition groups would have statistically significant SMRs if they differed from 100 by \pm 20 in males and \pm 15 in females. At area level, only seven condition groups for men and four for women reach statistical significance in the equivalent range. Only if SMRs were outside the range 50-150 would all groups be statistically significant for men and outside the range 65-135 for women. At district level, using three
Table 4 Number of years' data needed for SMRs in hypothetical populations to be statistically significant at the $5 \%$ level

\begin{tabular}{|c|c|c|c|c|c|c|}
\hline & \multicolumn{6}{|c|}{ SMR values } \\
\hline & 105 & 110 & 115 & 120 & 125 & 130 \\
\hline \multicolumn{7}{|c|}{$\begin{array}{l}\text { CARDIOVASCULAR } \\
\text { DISORDERS }\end{array}$} \\
\hline Region & 1 & 1 & 1 & 1 & 1 & 1 \\
\hline Area & 1 & 1 & 1 & 1 & 1 & 1 \\
\hline District & 3 & 1 & 1 & 1 & 1 & 1 \\
\hline \multicolumn{7}{|c|}{$\begin{array}{l}\text { RESPIRATORY } \\
\text { DISORDERS }\end{array}$} \\
\hline Region & 1 & 1 & 1 & 1 & 1 & 1 \\
\hline Area & 3 & 1 & 1 & 1 & 1 & 1 \\
\hline District & 10 & 3 & 2 & 1 & 1 & 1 \\
\hline \multicolumn{7}{|c|}{$\begin{array}{l}\text { MUSCULOSKELETAL } \\
\text { DISORDERS }\end{array}$} \\
\hline Region & 33 & 9 & 4 & 3 & 2 & 2 \\
\hline Area & 164 & 43 & 20 & 12 & 8 & 6 \\
\hline District & 573 & 151 & 70 & 41 & 28 & 20 \\
\hline \multirow{3}{*}{\multicolumn{7}{|c|}{$\begin{array}{l}\text { SYMPTOMS AND } \\
\text { ILL-DEFINED } \\
\text { CONDITIONS }\end{array}$}} \\
\hline & & & & & & \\
\hline & & & & & & \\
\hline Region & 21 & 6 & 3 & 2 & 1 & 1 \\
\hline Area & 104 & 27 & 13 & 8 & 5 & 4 \\
\hline District & 361 & 95 & 44 & 26 & 18 & 13 \\
\hline
\end{tabular}

years' data, SMRs less than 50 or more than 150 would be significant in only nine condition groups for men and 10 for women.

The importance of excluding real but statistically insignificant SMRs depends upon the resources that would accrue to a region or district from those SMRs. We have estimated the revenue resources which are shifted by a unit change in each condition-specific SMR by first calculating the proportion of total costed bed days made up by each condition group. Weighting these proportions by SMRs then gives the revenue allocation targets. If all SMRs are first set to 100 the proportion of revenue lost or gained by changing each SMR individually by one unit can be found.

For each hypothetical population these revenue effects of changing SMRs have been applied to the minimum SMRs which would be statistically significant over a given period. Five- and 10-year periods have been chosen because five-year post-reorganisation SMRs will be available for resource allocation purposes and RAWP recommended that 10 -year figures could eventually be used. Table 5 gives the revenue 'value' of the maximum non-significant condition-specific SMRs. These figures may be considered as indicative of the scale of change in revenue that results from including statistically non-significant SMRs in the calculation. The condition groups which shift the greatest proportion of the revenue are chapters 13 
Table 5 Percentage of NPIP revenue target which would be associated with maximum non-significant SMRs in three model populations

\begin{tabular}{|c|c|c|c|c|c|c|}
\hline \multirow[b]{2}{*}{ DISEASE GROUP } & \multicolumn{3}{|c|}{ 5-year SMRs } & \multicolumn{3}{|c|}{ 10-year SMRs } \\
\hline & Region & Area & District & Region & Area & District \\
\hline Infective & .09 & .22 & .47 & .07 & $\cdot 16$ & $\cdot 30$ \\
\hline Neoplasms & $\cdot 18$ & .13 & $\cdot 24$ & .04 & .09 & $\cdot 17$ \\
\hline Endocrine & .09 & $\cdot 15$ & $\cdot 30$ & .05 & $\cdot 10$ & $\cdot 20$ \\
\hline Haemopoietic & .06 & $\cdot 11$ & $\cdot 23$ & .03 & .07 & $\cdot 15$ \\
\hline Nervous system & $\cdot 24$ & .39 & $\cdot 78$ & $\cdot 19$ & $\cdot 27$ & $\cdot 53$ \\
\hline Cardiovascular & $\cdot 10$ & $\cdot 17$ & $\cdot 32$ & .05 & $\cdot 12$ & $\cdot 23$ \\
\hline Respiratory & .05 & $\cdot 13$ & .26 & .04 & .09 & .41 \\
\hline Digestive & $\cdot 15$ & .39 & .76 & $\cdot 12$ & $\cdot 27$ & $\cdot 52$ \\
\hline Urogenital & $\cdot 17$ & $\cdot 23$ & .46 & .05 & $\cdot 16$ & $\cdot 30$ \\
\hline Musculoskeletal & $\cdot 33$ & .65 & $1 \cdot 35$ & $\cdot 19$ & .44 & .89 \\
\hline Congenital & .07 & $\cdot 16$ & $\cdot 32$ & .05 & $\cdot 11$ & $\cdot 21$ \\
\hline Perinatal & .05 & $\cdot 10$ & $\cdot 20$ & .03 & .07 & $\cdot 14$ \\
\hline $\begin{array}{l}\text { Symptoms and } \\
\text { ill-defined } \\
\text { Injuries and }\end{array}$ & $\cdot 33$ & .75 & 1.55 & $\cdot 22$ & $\cdot 52$ & 1.03 \\
\hline accidents & $\cdot 18$ & $\cdot 30$ & $\cdot 59$ & .09 & $\cdot 21$ & $\cdot 37$ \\
\hline
\end{tabular}

(musculoskeletal disorders) and 16 (symptoms and ill-defined conditions). However, in general, non-significant SMRs are relatively inexpensive.

\section{Discussion}

Attention has been drawn to the possible distorting effects upon regional and district allocations of random variations in yearly deaths. If these variations are taken into account by including only SMRs which differ from 100 by more than two standard errors, allocation patterns would change. At regional level the effect is small: about $0.5 \%$ of revenue target allocations for non-psychiatric in-patients. Such changes may seem relatively unimportant and could be accommodated without great disruption. The effect at district level has been explored in one region. Our estimates suggest that the effect of non-significant SMRs is of the order of $2.5 \%$ of a district's NPIP revenue target when three-year mortality data are used.

The issues discussed so far may not be generally accepted because the concept of the statistical significance of SMRs may seem contentious. The choice of the $5 \%$ level as a test of statistical significance is conventional but arbitrary. Choosing a different probability value would almost certainly alter allocations.

Another objection which might be raised by health authorities is that SMRs are statistically non-significant only because insufficient data have been accumulated since reorganisation of the National Health Service. If we were to accept this criticism, and calculate how many years' data would be needed to achieve statistical significance for SMRs at particular values, there would be an important consequence. It has been shown that within certain condition groups only very large mortality differences are counted as significant even when five or 10 years' data are used. However, the resource consequences of their removal are comparatively small.

Here, then, is the present dilemma. The price paid for reducing randomness in the RAWP formula is a reduction in the sensitivity of the allocation process to possibly real but non-significant SMRs, accounting perhaps for up to $2.5 \%$ of NPIP revenue targets. However, it is not at all clear how non-significant real mortality differences could be justified, and perhaps authorities should err on the side of caution by including only statistically significant SMRs. As additional years' data become available, the size of the problem will be reduced and the resource consequences of statistical significance will largely disappear. But our method provides a basis on which regions which have not already done so can assess the resource consequences of statistical unreliability ando so reduce the randomness in RAWP.

Reprints from Dr. S. Palmer, Public Healtho Laboratory Service, Communicable Diseasê Surveillance Centre, 61 Colindale Avenue, Londop NW9 5EQ.

\section{References}

${ }^{1}$ Department of Health and Social Security. Sharing Resources for Health in England. Report of the Resource Allocation Working Party. London: HMSO, 1976.

${ }^{2}$ Geary K. Technical deficiencies in RAWP. Br Med J 1977; i: 1367.

${ }^{3}$ Ferrer HP, Moore A, Stevens GC. The use of mortality data in the Report of the Resource Allocation Working Party. Public Health 1977; 91: 289-95.

4 Armitage P. Statistical Methods in Medical Research. Oxford: Blackwell, 1971.

${ }^{5}$ Chiang CL. Standard error of the age-adjusted death rate. In: Vital Statistics. Special Report No. 47. Washington DC: United States Department of Health Education and Welfare, 1961: 271-85.

${ }^{6}$ Office of Population Censuses and Surveys. 1974 Mortality Statistics: Area. Series DH5 No. 1. London: HMSO, 1976.

${ }^{7}$ Office of Population Censuses and Surveys. 1975 Mortality Statistics: Area. Series DH5 No. 2. London: HMSO, 1977.

${ }^{8}$ Office of Population Censuses and Surveys. 1976 Mortality Statistics: Area. Series DH5 No. 3. London: HMSO, 1978. 